\title{
Ensinando História da Computação com foco no protagonismo das mulheres com jogo Computasseia: Um relato de experiência com ingressantes de Engenharia de Software e Ciência da Computação
}

\author{
Valéria Maria Pinheiro, Ana Iza Alencar, Karina Castelo Branco, Maria Victória \\ Fiori, Anna Beatriz Marques \\ Universidade Federal do Ceará (UFC) - Campus Russas \\ Russas - CE - Brasil \\ \{valeriam.soft, anaizaalencar, karinascb, victoria.fiori\}@alu.ufc.br, \\ beatriz.marques@ufc.br
}

\begin{abstract}
There have been strategies to enhance women's representation in various contexts in order to reduce prejudice against women in Science and Technology. This paper reports an experience with the game Computasseia to divulge women's protagonism in Computing for students entering Software Engineering and Computer Science courses. The results indicated that the game contributed to the increase in the perception of learning about the female personalities of Computing after using the game.
\end{abstract}

Resumo. Estratégias para potencializar a representatividade feminina em diversos contextos vêm sendo realizadas com o intuito de reduzir o preconceito sobre a atuação de mulheres na Ciência e Tecnologia. Este artigo relata uma experiência com o jogo Computasseia para divulgar o protagonismo das mulheres na Computação para estudantes ingressantes de cursos de Engenharia de Software e Ciência da Computação. Os resultados indicaram que o jogo contribuiu para o aumento sobre a percepção de aprendizado sobre as personalidades femininas da Computação após o uso do jogo.

\section{Introdução}

Silva et al. (2019) apontam que existe um preconceito de que as mulheres são consideradas inábeis para as áreas científicas, preconceito que se estende para o campo das tecnologias. Tal preconceito pode estar relacionado à falta de informação sobre mulheres pioneiras na área de Tecnologia, como Ada Lovelace, Grace Hopper, Anita Borg, dentre tantas outras.

Como estratégia para divulgação dessas mulheres pioneiras, Figueiredo e Santos (2016) criaram um jogo de cartas para o ensino de História da Computação denominado Computasseia, que resgata várias personalidades femininas pioneiras da área. Tal jogo caracteriza-se como um jogo educacional não-digital que pode ser empregado em diferentes níveis de ensino para divulgar o protagonismo das mulheres na História da Computação. Jogos educacionais não-digitais promovem um ambiente de interação social e imersão dos estudantes sobre a tarefa de aprendizagem (Petri et al., 2018).

Marques et al. (2019) identificaram que um dos fatores que levam alunas a desistirem de cursos da área da Computação é a falta de identificação com o curso, o que pode ser ocasionado pelo fato de serem minoria em suas turmas. Mello et al.(2019) 
apontam que além da falta de identificação com o curso, a falta de divulgação de protagonistas mulheres justifica o ingresso pouco expressivo de mulheres na área. Neste sentido, este artigo apresenta um relato de experiência com o jogo de cartas Computasseia em duas turmas ingressantes dos cursos de Engenharia de Software e Ciência da Computação da Universidade Federal do Ceará - Campus de Russas. O objetivo da experiência foi desconstruir desde os primeiros contatos com o curso e a universidade, a ideia de que as mulheres não exercem posições de protagonistas na área de tecnologia. Um questionário foi adotado para avaliar a percepção sobre o conhecimento a respeito de personalidades femininas antes e depois do jogo.

O restante deste artigo está organizado da seguinte forma: a Seção 2 apresenta o Computasseia e regras do jogo. A metodologia adotada na experiência é descrita na Seção 3. Na Seção 4 são discutidos os resultados obtidos a partir da experiência. Por fim, a Seção 5 apresenta as considerações finais e lições aprendidas.

\section{Computasseia}

O Computasseia é um jogo de cartas desenvolvido para dar apoio ao ensino da história da Computação, pensado para diminuir a dificuldades enfrentadas por docentes no ensino história da Computação [Figueiredo e Santos 2016]. O jogo possui um conjunto de 60 cartas onde cada carta representa um acontecimento ou personalidade importante para a história da Computação, além de serem divididas em categorias e áreas de conhecimento. As cartas possuem elementos gráficos que facilitam o entendimento do conteúdo abordado e instigam a curiosidade como: título, imagem ilustrativa, área de conhecimento, categoria, descrição e data (Figura 1). Tratando-se de um jogo de estratégia, o objetivo do jogo deve ser alcançado por meio da distribuição sequencial em ordem crescente da data das cartas, desta forma uma linha do tempo é criada (Figura 1).
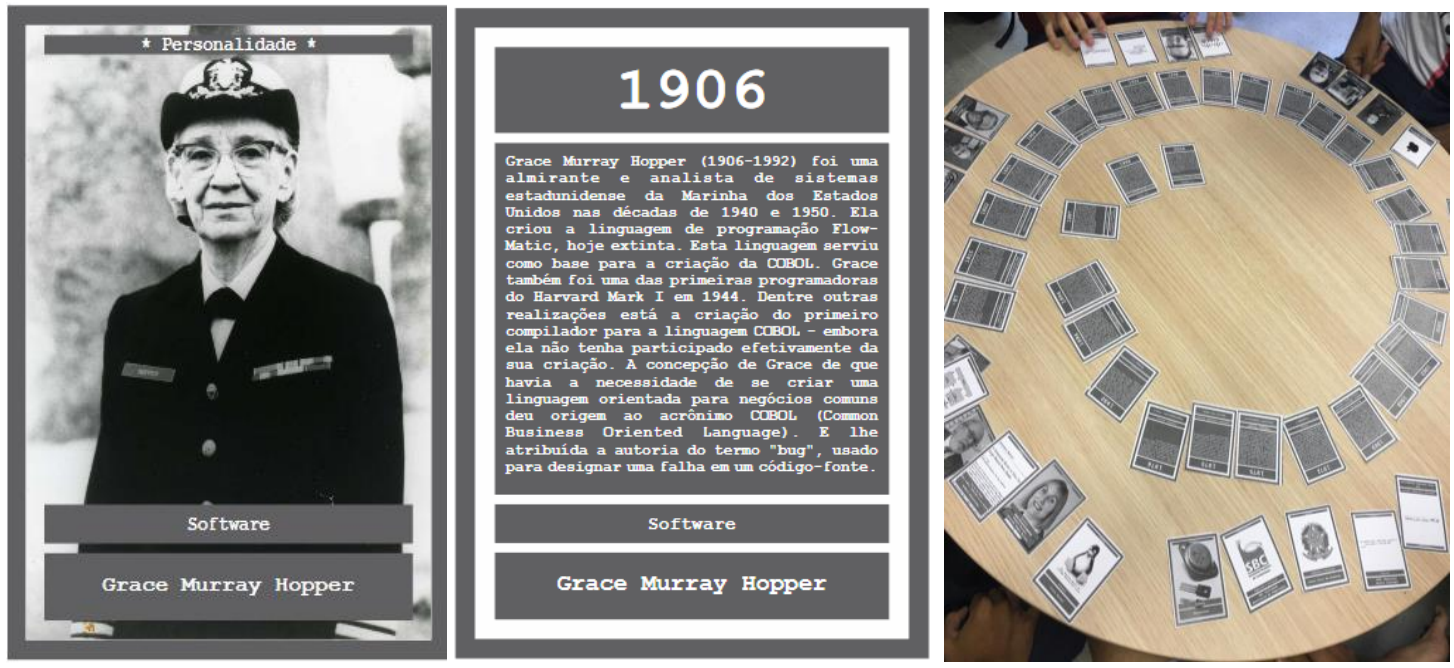

Figura 1. Exemplo de cartas e seus elementos e linha do tempo formada com as cartas.

O jogo pode ser realizado com equipes de dois a seis jogadores e deve ser iniciado com cada jogador recebendo seis cartas aleatórias, as demais cartas ficam empilhadas em um montante de cartas, com a visão frontal da carta voltada para cima. Para a criação da linha do tempo deve, um por um dos jogadores, escolher uma das cartas de sua mão para utilizar na jogada e deve tentar inseri-la no local que julga ser o correto na linha do tempo. 
Em seguida, a carta pode ser virada revelando a data e suas informações, permitindo a verificação de um acerto ou erro do jogador.

No caso de erro, a carta permanece na linha do tempo, porém na posição correta e o jogador retira mais uma carta do montante de cartas. $\mathrm{O}$ próximo jogador inicia a próxima jogada. O jogo termina quando um dos jogadores consegue descartar todas as cartas de sua mão, sendo declarado o vencedor ou quando o montante de cartas se esgota. Neste caso, o vencedor é o jogador com o menor número de cartas em mãos.

O Computasseia é um jogo que pode ser utilizado em diversos níveis de ensino: técnico, graduação e pós-graduação [Figueiredo e Santos 2016]. Alencar et al (2019) realizam uma experiência com o Computasseia em turmas de ensino médio e graduação e como resultados obtiveram que o jogo contribuiu para o ensino da História da Computação, além de tornar o processo de aprendizagem mais interativo e dinâmico. Com o jogo também foi possível apresentar ao estudantes a participação feminina na área de TI durante toda a História da Computação.

\section{Metodologia}

A experiência foi conduzida pelo projeto Meninas Digitais do Vale, um projeto parceiro do Programa Meninas Digitais que atua na Universidade Federal do Ceará - campus de Russas. O jogo foi adotado em duas turmas de ingressantes de Engenharia de Software e Ciência da Computação nas disciplinas "Introdução à Engenharia de Software" e "Introdução à Ciência da Computação". Cada turma possuía em média 50 estudantes, por isso as turmas foram divididas em dois grupos, para que fosse possível utilizar a sala de metodologias ativas da universidade, que possui capacidade para 25 a 30 estudantes.

Inicialmente, as alunas do projeto realizaram uma aula expositiva sobre a História da Computação. Com a aula os estudantes puderam entender um pouco sobre o conteúdo que iria ser abordado pelas cartas. Logo após, o grupo de estudantes foi dividido em equipes com até seis participantes. Nesse momento, se formaram cinco equipes.

A primeira etapa da experiência compreende a apresentação sobre o jogo. Após a apresentação e o ensinamento de como jogar, as cartas foram distribuídas e os estudantes começaram a jogar. A experiência com o jogo tinha que ter duração de até 2 horas, que corresponde à duração de uma aula da disciplina. A terceira etapa do processo, consiste na premiação dos vencedores, onde os prêmios eram bombons, bottoms ou adesivos. A quarta etapa, consistiu na aplicação dos questionários de avaliação do jogo. Os questionários possuíam perguntas sobre o nível de conhecimento dos estudantes em relação às personalidades femininas antes e depois da realização do jogo.

\section{Resultados}

O Jogo Computasseia apresenta mulheres protagonistas da História da Computação. Dessa forma, decidiu-se investigar com os estudantes, sobre o seu conhecimento antes e depois da experiência com o jogo, em relação às 13 mulheres que aparecem nas cartas. Os resultados são apresentados na Figura 2. 


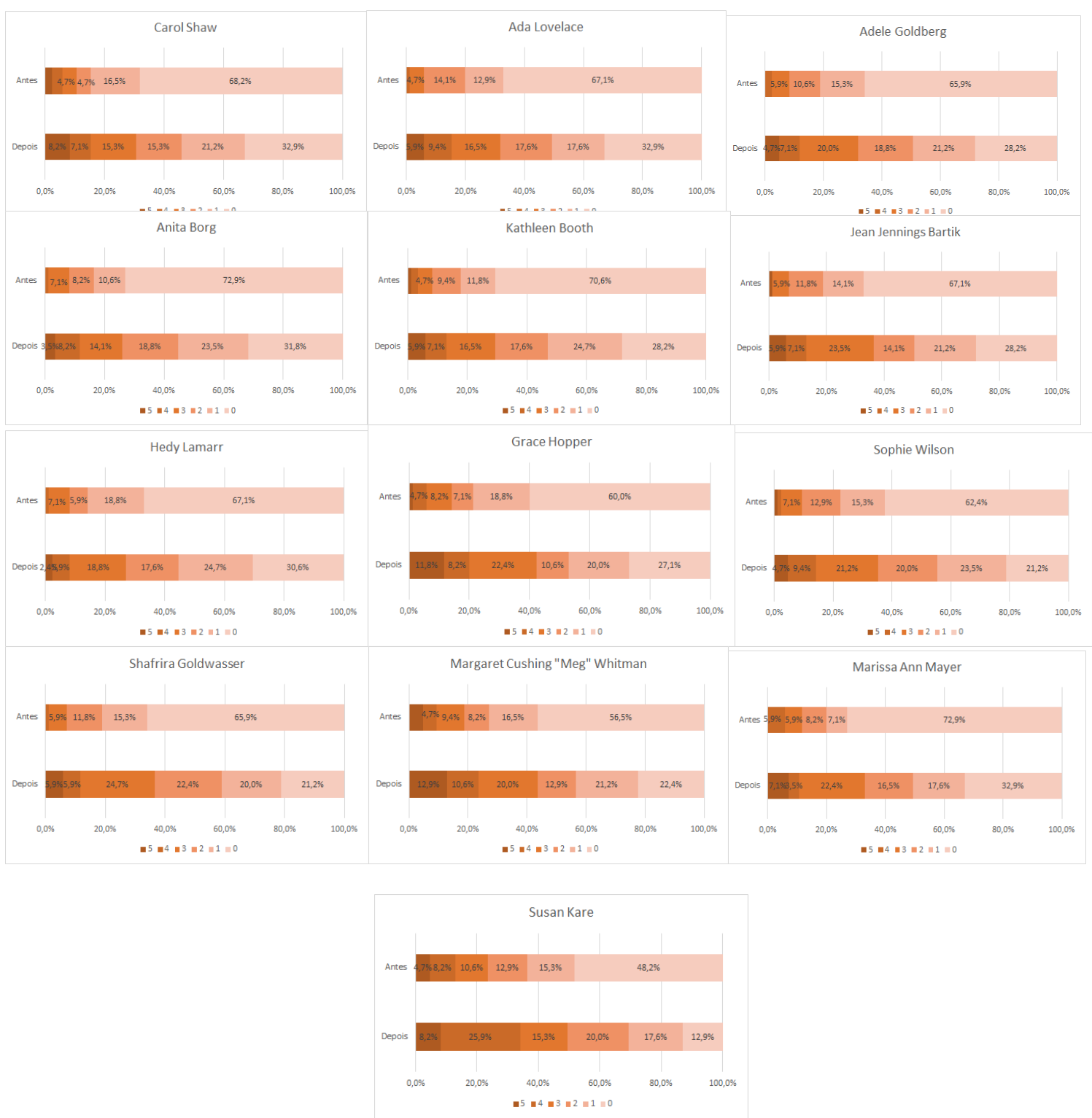

Figura 2. Resultados sobre o grau de conhecimento antes e depois do jogo

Sobre a Ada Lovelace, $67,1 \%$ dos estudantes indicaram conhecimento nulo (0) antes do jogo, e após o jogo 67,1\% indicaram conhecimento baixo (1), médio (2), alto (3) e altíssimo (5). Em relação a Adele Goldberg, 65,9\% dos estudantes consideravam seu conhecimento nulo antes do jogo, após o jogo, somente $28,2 \%$ dos estudantes permaneceram com o conhecimento nulo. Susan Kare foi a personalidade feminina que apresentou maiores indicações de conhecimento, 51,8\% dos estudantes indicaram algum conhecimento sobre ela e após o jogo esse número subiu para $87,1 \%$.

Os dados mostram que a percepção dos estudantes sobre o nível de conhecimento sobre todas as mulheres presentes nas cartas do jogo aumentou depois da utilização jogo. Porém, os dados também mostram que, mesmo após a utilização do jogo, ainda houve algum grau de conhecimento nulo, mas reduziu após a experiência. Isso pode acontecer devido ao jogadores, em algumas situações não realizarem a leitura do verso das cartas, com informações sobre as personalidades. Esses jogadores acabam focando na dinâmica de montar a linha do tempo e nem sempre focando no aprendizado. 


\section{Considerações Finais e Trabalhos Futuros}

Este trabalho teve como principal objetivo a aplicação e avaliação de um jogo de cartas que mostra os principais fatos e personalidades importantes da História da Computação. O jogo Computasseia foi selecionado porque resgata mulheres protagonistas da Computação, em sua maioria, desconhecidas devido à falta de informação. Com base nos resultados obtidos, observou-se que o jogo apresenta personalidades femininas que eram desconhecidas para mais de $60 \%$ dos estudantes que participaram da experiência. Neste sentido, a experiência com o jogo contribuiu para divulgar o protagonismo feminino na Computação, desmistificando a ideia de que as mulheres não podem exercer posições de protagonistas na área. Como sugestão de melhoria, o design das cartas poderia ser reprojetado para que parte do conteúdo fosse disposto na frente da carta e não somente no verso.

O uso do jogo de cartas Computasseia para o ensino da História da Computação representou uma possibilidade diferente de ensino para introduzir conhecimentos históricos sobre a área na qual os estudantes estão cursando, visto que a História da Computação é marcada por grandes mulheres e usamos isso como um incentivo à permanência das mesmas nos cursos. Como trabalhos futuros pretendemos aplicar, após a experiência com o jogo, um quiz sobre o conteúdo abordado no jogo.

\section{ReferÊncIAs}

Alencar, A., Pinheiro, V., \& Marques, A. (2019). Promovendo o conhecimento sobre mulheres na Computação: experiência com o jogo de cartas Computasseia no ensino de História da Computação. In Anais do XIII Women in Information Technology, (pp. 139-143). Porto Alegre: SBC. DOI: https://doi.org/10.5753/wit.2019.6725.

Figueiredo, S., Santos, O. (2016). Computasseia: destacando a participação feminina na História da Computação. In Anais do XIII Women in Information Technology, (pp. 16-19). Porto Alegre: SBC. DOI: https://doi.org/10.5753/wit.2016.9692.

Marques, A., Pinheiro, V., Alencar, A., Branco, K., Alves, R., \& Mendes, M. (2019). Unindo pesquisa e extensão para fortalecer a participação feminina em cursos de Computação de uma universidade: Projeto Meninas Digitais do Vale. In Anais do XIII Women in Information Technology, (pp. 31-40). Porto Alegre: SBC. doi:10.5753/wit.2019.6710

Mello, A., Melo, A., \& Ferrão, I. (2019). Uma análise sobre questões de gênero nos cursos de Computação do município de Alegrete/RS. In Anais do XIII Women in Information Technology, (pp. 61-68). Porto Alegre: SBC. doi:10.5753/wit.2019.6713

Petri, G., Calderón, A., von Wangenheim, C., Borgatto, A., \& Ruiz, M. (2018). Benefícios dos Jogos Não-Digitais no Ensino de Computação. In Anais do XXVI Workshop sobre Educação em Computação. Porto Alegre: SBC. doi:10.5753/wei.2018.3481

Silva, J., Oliveira, L., \& Silva, A. (2019). Meninas na Computação: uma análise inicial da participação das mulheres nos cursos de Sistemas de Informação do estado de Alagoas. In Anais do XXVII Workshop sobre Educação em Computação, (pp. 444452). Porto Alegre: SBC. doi:10.5753/wei.2019.6649 